\title{
Cellular Therapy, an Autologous Cellular Point of Care Approach to Satisfy Patient Needs
}

\author{
*Falk Heinrichsohn \\ Stem Cell Consultant, Germany
}

Submission: May 26, 2017; Published: July 13, 2017

*Corresponding author: Falk Heinrichsohn, Stem Cell Consultant, Germany, Tel: 351924087 637; Email: falk.heinrichsohn@live.com

\begin{abstract}
Cellular therapy is a therapy in which either cellular material is injected into a patient or cells are stimulated by energy related fields. This review is giving an overview of the regulatory environment and approach in different countries towards the 21st Century, state of the art but also disruptive medical treatment technology. Main focus is however, on autologous cellular therapy. Autologous cellular therapy is already considered in many countries, like Japan, Australia, India, but also Panama or the Bahamas, as a safe medical alternative, also when performed in a point of care setting in the responsibility of a physician with consent of the patient being treated.

This approach is substantially different from the approach of evidence based medicine, which is treating symptoms with approved, heavily manipulated, chemical and biological based pharmaceutical drugs, whereas cellular therapy is trying to boost the natural regenerative capability of a human body with own cells and the energy related stimulation of own cells. We each time more understand that human beings are energy beings, and if we understand well the bioelectric language cells communicate, we can treat the condition on its root cause. Own stem cells, having all the information of the body stored, are therefore the most qualified source to communicate in the body and to treat a condition of a patient in the most natural way.
\end{abstract}

Various "Smart Countries" have already accepted that cellular treatment is much different from traditional treatment with pharmaceutical drugs and have changed their regulation in order to bring the new science based technology more quickly to the market place by implementing specific regulations for regenerative medicine and in addition separate regulations for point of care treatment with autologous cellular treatment methods. This certainly does not mean that they are neglecting the principles of consumer protection but use global information to review and in the end value differently the risk benefit of such modern treatment to help patients with unmet medical needs.

A consequence of a restrictive interpretation of advanced cellular treatment is, that, besides it can be seen as being not a patient centred and patient friendly policy, it also is resulting in a loss of new applied medical PoC know-how in over-regulated countries. Many countries, without jeopardizing the need of consumer protection, have treated already thousands of patients with very few to non-serious side effects and enjoy medical tourism to help patients with unmet medical need, while patients wonder each time more why they cannot have the same treatment in their home country.

Abbreviations: CAM: Complementary and Alternative Medicine; MSC: Mesenchymal stem cells; RMT: Regenerative Medicine Therapy; RAT: Regenerative Advanced Therapy; TGA: Therapeutic Goods Administration; WMA: World Medical Association; PoC: Point of Care

\section{Background}

Existing evidence based medicine, has shown its limitation in treating especially chronic medical conditions, as new pharmaceutical drugs, also due to complex regulatory environment in the US and Europe especially, are only approved after a long investigational time period and expensive clinical trial regulation to eventually treat symptoms.

Humans are, as we know since some time, a complex biological, energy related system manifested in a material field (Figure 1) of about 100 Trillion cells, surrounded and embedded in various energy related structures, communicating with its specific neural network, able to exchange and analyse information and with this, initiating impulses triggering biological, electrical and chemical related reaction at its cellular structure.Cellular treatment, Complementary and Alternative medicine (CAM) therapy are a potential alternative, even a disruptive, medical treatment in a Point of Care setting to support a chronic ill and aging population, where standard medical treatment has clearly shown it limitations. 


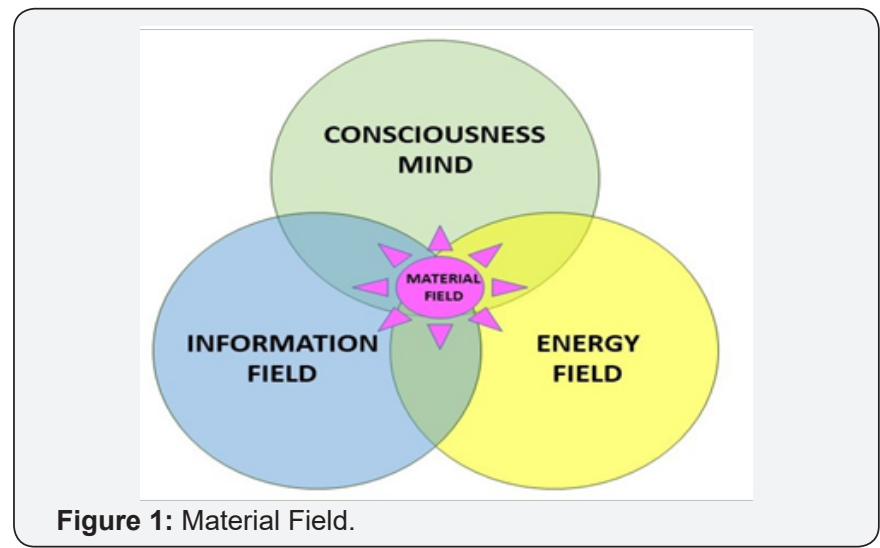

Even GSK and Alphabet, the mother company of Goggle, have announced in December 2016 to form a J/V, investing about 700 million USD to explore and develop bioelectronics. Many other companies explore the biofeedback and information field therapy. The Electronic giant Qualcomm, announced the "Qualcomm Tricorder 10 Million USD XPRIZE" and is challenging teams to develop between 2012 to 2017, a radical innovation in health care that turns science fiction into reality. What makes the tricorders being developed in this competition different is that no one else in the world is working toward a portable, wireless device, based on a star trek vision, that can diagnose a myriad of conditions, plus continuously monitors five vital signs; something that has never been done before, later on even treatments are envisioned.

Before going into cellular and CAM treatment potentials, I like to reflect on the development of medical treatment and regulations having the character to protect consumers from not qualified drugs. Research is an important part of this development and for me Research is a philosophical activity, as we try to understand better, new frontiers, to ultimately improve quality of life of humans and to reach the next step in the development of Homo sapiens, which comes from Latin and means "Wise Man". Humans are also patients, and from a patient point of view, accepted by many countries already, we should divide technological advances in medicine into two new main fields of application with adequate regulation, without neglecting proven valid regulations for heavily manipulated chemical and biological drugs, and open up, the pathway for autologous cellular treatment to support the body's natural capability to heal itself.

Different to the present drug technology and its regulation, autologous cells have a high natural safety profile $[2,3,4,5]$ as they are technical separate from the same body (mainly Bone Marrow or Adipose Tissue) and returned to the same body without further manipulation. In practice, we are talking about increasing the number of own stem cells which had been dormant, to increase the body's regeneration capability, without having to observe immunoreactions. As shown in the diagram over time we are using up certain cellular population, especially Mesenchymal stem cells (MSCs) (Figure 2) in our body resulting that the body cannot defend as well as in young age the body from cellular defects and aging.

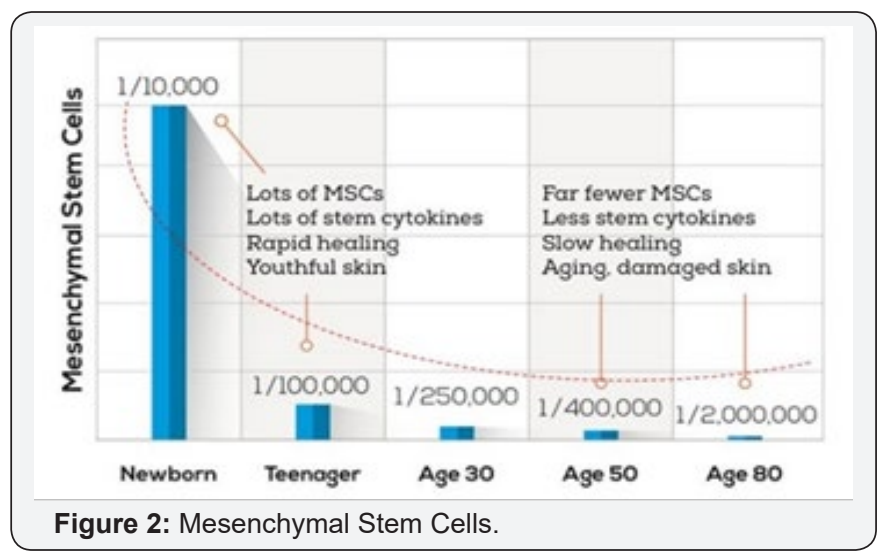

\section{Regulations \& Consumer Protection}

In the below charts the present basic regulatory environment in the US and Europe is shown. The FDA regulates drugs, devices and supplements but does not regulate the Practice of Medicine, though drug regulation may try to influence PoC. In the US, in December last year, the "21st Century Cures Act" had been approved and was "inserted" into the existing drug regulation (Figure 3). If a cell-based product is now classified as a Regenerative Medicine Therapy (RMT), it is eligible for new designation "Regenerative Advanced Therapy" (RAT), which expedites approval process [1]. However, two more criteria must be met for RAT designation:

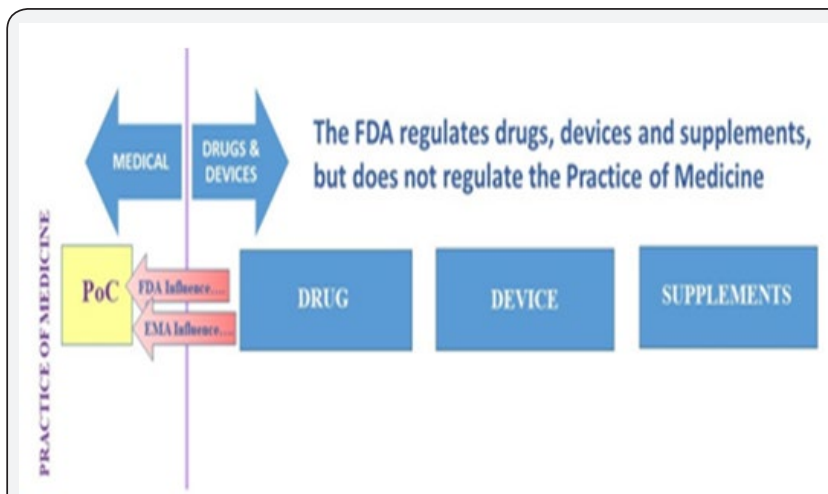

Figure 3: The FDA Regulates drugs, devices and Supplements, but does not regulate the practice of medicine.

a. Serious or life-threatening disease or condition and

b. Preliminary clinical evidence indicates that the drug has the potential to address unmet medical needs for such a disease or condition.

Once RAT is granted, developer will enjoy all the same benefits that Breakthrough Therapy designation offers, 
including two more existent expedited programs - Accelerated Pathway and Priority Review. Various countries have already changed their regulation, and Japan already in 2004 reflected on the 21st century advancement in medical treatment. What does this mean? Japan has developed a specific regulation and implemented it in 2004, (Figure 4) for regenerative adult stem cell treatments. The new legal framework recognized that Stem Cell therapy is a unique form of treatment that does not appropriately belong to the existing approval pathways of "biologics and drugs".

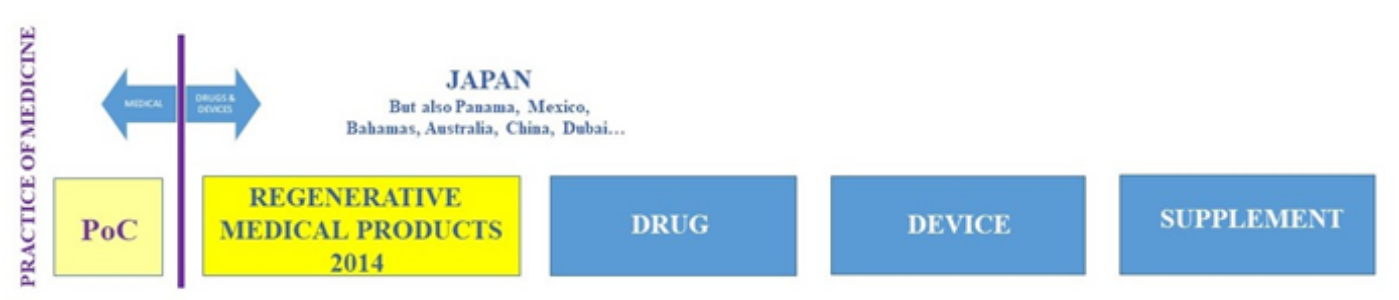

Figure 4: Japan specific regulation

Here is an example illustrating the difference to the US and EU regulation. In Japan, a Bio-company, harvested via muscle biopsy stem cells, expanded them, and supplied them in a kit form to a hospital who produced cell sheets for being transplanted to the heart, to treat Ischemic Heart Disease (Figure 5). The product application for marketing was made in September 2014, and approved one year later in September 2015, under the condition of doing a five-year long post marketing and efficacy study. As in the US, phase three has to be performed before the approval; years will pass, while others already treat patients with unmet medical need and investigational medicine.

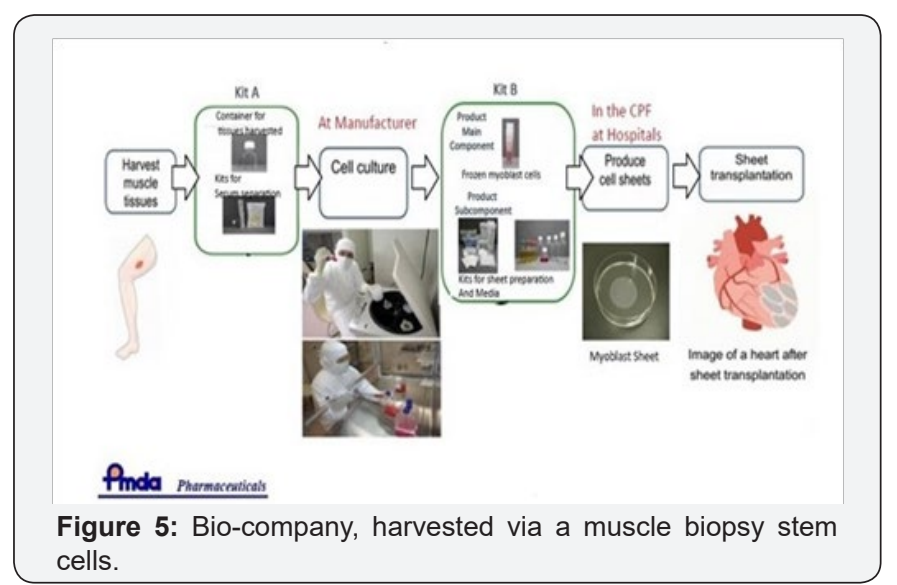

The same logic was suggested by the "Regrown Act" last year (2016) but did not win the approval in the house. Irony is, that the Japanese model was suggested, many years back already, in the US by a former FDA director. Considering this legal framework for the same "medical treatment possibility" the US and Europe are lagging years in bringing advanced medical cellular therapies to the market. Besides this, those countries have clearly separated autologous stem cell treatment as a "Point of Care, Medical Procedure" from drug regulations, as practice of medicine, whereas the FDA and EMA tries to develop guidelines to stop this technology which has shown impressive results in more than 500 clinics operating globally.
Evidence based medicine of the 20th century has undoubted, considerable improvement of quality of life of humans, but like everything which is developing, sometimes things go wrong like in 1901, where contaminated small pox vaccines in the US, produced by the emerging pharmaceutical industry, caused the death of various children. This, as we all know from history, resulted into the Biological Act of 1902, seen today by many as the start of federal regulations, requiring pre-marketing approvals. Europe and other countries followed this US philosophy and policy in the early 20th century. Today as shown above we have regulations in place for pharmaceutical drugs, devices and supplement still reflecting the philosophy of the needed Biological Act of 1902! Technology and knowledge in the last 100 years, however, changed dramatically and regulations tried to follow these fast changes to combine medical advances and the needed philosophy of consumer protection. Certainly, a quite difficult task, influenced by the different economic interests of the various stakeholders involved in developing, marketing and approving new evidence based products. Ethics, when it comes to cellular medicine also play an important role influencing politics and regulations considerably in the US and Europe.

Patients today however, due to the information capability via the internet are better informed about a potential treatment of their conditions and question the advice of a medical professional, especially if the suggested standard medical treatment does not show the improvement expected, and cellular treatment which is allowed in other countries, showing improvements of "Quality of life", are considered by local medical professionals as dangerous, because they are not approved in the country! The not invented here syndrome creates many doubts why regulators support only one medical pathway, while others advance with new scientific insights! Chronic conditions are undoubted difficult to treat with the presently available evidence based medicine, as those treatments do not affect the root cause of the condition. Therefore patients with unmet medical need look intensively for alternatives which often results into medical tourism. I do 
not like to enter the discussion whether it is right or wrong, fact is however, that unmet medical need somewhere is addressed, treated, and marketed with testimonials of individuals showing interesting improvements of their condition. Those clinics doing autologous stem cell treatments have published $[2,3,6,7,8]$ showing the safety profile and improvements, but as those studies are not following the regulatory requirement of blinded studies, to evaluate placebo effects, they are not accepted in the evidence based policy environment.

What we can see, is that various "Smart Countries" have changed their regulation in order to bring the new science based technology more quickly to the market place. Does this mean that they neglect the principles of consumer protection, certainly not! Those smart countries have understood that "regenerative medicine" is completely different from the standard chemical and biological treatment regime used so far to improve quality of life of people. What they changed is very simple:

a) The standard rule for chemical and biological heavily manipulated products with the philosophy one drug fits all patients with the same symptoms stays unchanged

b) Regenerative medicine which works with the cellular structure of humans is a complete separate regulation as it cannot be embedded into the standard clinical trial pathway as it comes close to personalized treatment technology.

c) Medicinal cellular treatment in a Point of Care setting, in the responsibility of a physician, with personalized consented treatment of a patient with own, autologous, cellular structure is not embedded in the drug or regenerative medicine regulation, but regulated by the medical boards within the medical procedure regulations for physicians.

Stem cells harvested from a person, minimally manipulated, and returned back to the same person in a medical procedure is clearly a personalized treatment and has nothing to do with products industrialize produced and scheduled to treat illnesses by being sold via companies to a market to treat patients with certain illnesses. Even though, the FDA tries to interfere in the practice of medicine with new "unbinding guidelines", the CURRENT Federal Code of Regulation 1271. 15b clearly states "The Reimplantation of AUTOLOGOUS HCT/P during the same surgical procedure is the Practice of Medicine". In Australia, the Therapeutic Goods Administration (TGA) is responsible for the regulation of products including human cells and tissues (termed 'biologicals'). This includes human stem cell treatments.

However, the TGA does not regulate medical practice. For this reason, some products that would otherwise be considered biologicals are excluded from TGA regulation (through the Therapeutic Goods (Excluded Goods) Order No. 1 of 2011). Under this provision stem cell treatments may not be subject to regulation by TGA if they are human cells that are collected, processed and returned to the same patient, in a single course of treatment while under the clinical care and supervision of a registered medical practitioner. Also, here the World Medical Association (WMA) declaration of Helsinki is clearly reflected.

Even in the EU it should be possible. EMA stipulates in their regulation that stem cells are drugs. In Directive 2001/83/EC it is stated that "The scope of this Regulation should be to regulate advanced therapy medicinal products which are intended to be placed on the market in Member States and either prepared industrially or manufactured by a method involving an industrial process". Those industrialized produced ATMPs have to follow the present drug regulation, i.e. it requires a pre-marketing approval.

As point of care procedures are personalized medical treatments, the use of cellular products is a medical procedure and not an industrialized produced product, being regulated by EMA or the FDA before sold in the market. Point of care products are individually processed for one person only and not reproduced to be sold to third parties in the market $[2,4,6,10]$. In various European countries exist regulations where those activities are considered as an established medical activity and has a kind of "grandfather regulation status" showing clearly that cellular treatments in a point of care setting is outside the EMA regulation. An example is the Austrian regulation as stipulated in the: "Gewebesicherheits gesetz-GSG" as in § 49. Federal Act, (machine translation) a federal law laying down standards of quality and safety for the collection, processing, storage and distribution of human cells and tissues for use in humans (tissue safety law GSG) will be adopted, with the medicines Act, the reproductive medicine Act, the health and food safety law and the Federal law on hospitals and sanatoria and changed accordingly. The National Council has decided in its Article 1, that the Federal Law, is laying down standards of quality and safety for the collection, processing, storage and distribution of human cells and tissues for use in humans in its "Tissue safety law GSG".

\section{This regulation stipulates in article}

a. This federal law regulates the extraction of human cells and tissues for use in humans. It also defines the processing, storage and distribution of human cells and tissues for use in humans, if this is not used for the manufacture of medicinal and investigational medical devices.

b. In the collection, processing, storage and distribution of human cells and tissues the state of science and technology shall comply.

c. This act / regulation do not apply for cells and tissues that are used as an autologous graft within the same medical procedure. 
This above-mentioned selection of regulations is already well accepted by many countries and do not only supports patients with unmet medical needs but also supports the science based medical treatment policy to bring cell based products quickly to the market and helps physicians working already in point of care settings to develop that science based investigational treatments further [7].

\section{Method}

Besides therapies to stimulate the cellular structure with Bioelectric, pulsed electromagnetic Frequency (PEMF) and Laser- therapy we have two main pathways to treat patients with stem cell treatments (Figure 6). First pathway is highly manipulated allogeneic, gene and autologous cellular products, administered oral, or via IV, intramuscular, intrathecal alone or in combination, which need still to follow the present regulatory 12 - 15-year review including clinical trials after all safety and efficacy concerned had been eliminated. Japan and others have however, already changed their approach to cellular treatment by accepting first promising safety results for a pre-marketing approval within basically one year of application followed by a 5-year post marketing review to confirm primarily promising results.

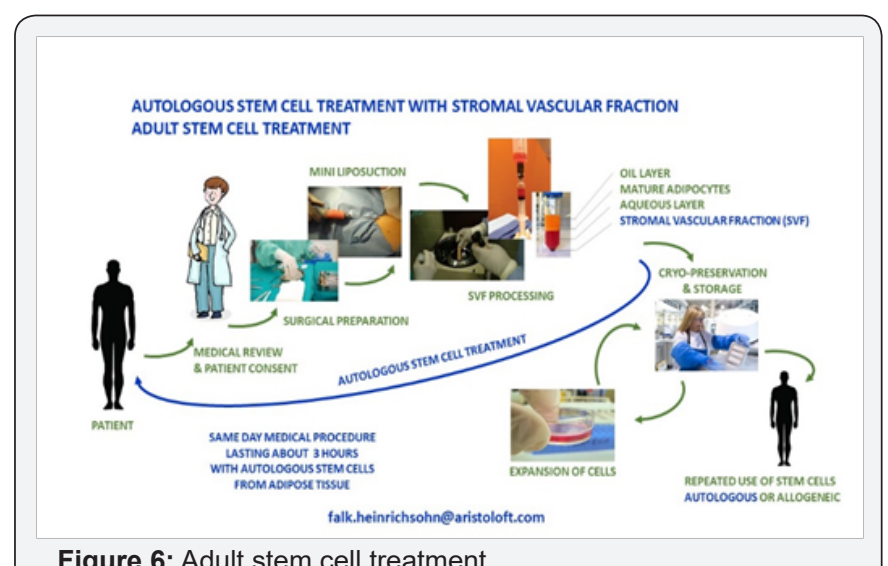

Figure 6: Adult stem cell treatment.

Second very promising pathway which is developing globally very quickly is to administer autologous cellular products from the same person in a medical procedure to support the natural regeneration capability of human cellular structure. This method is being considered by various scientists and many medical societies as the fastest way to personalized medicine with very limited to no side effects, readily available today, but still questioned by some scientist due to its investigational character and potential safety and efficacy concerns. There are however numerous studies having clearly indicated that autologous stem cell treatment is safe, provided they are administered by medical professional with specific equipment support, providing a practically contamination free processing environment [9].

\section{Conclusion}

Based on the current scientific knowledge of risk -benefit of cellular treatment, countries mainly outside the FDA / EMA regulated territory, advanced approved, respectively accepted autologous cellular treatments for patients, even via expansion of own cells. In the US, autologous stem cell treatments in the frame of practice of medicine is so far tolerated, but critically reviewed by the FDA with a trial to implement new regulatory guidelines, limiting those "Point of Care" stem cell treatments.

The 21st Century Cures Act, in the US, is a step in the right direction to catch up with countries having already adopted new policy and regulations for regenerative medicine, but does not clarify the most controversial issue in the US cell therapy, the Point of Care (PoC) treatment, highly debated in a historic FDA public hearing in September 2016. EMA's policy in Europe is similar to the US, while other countries are clearly advancing further and faster with disruptive cell, stem cell and CAM technologies. Japan and other countries open to changes have already shown a five to more year advantage when it comes to developing, marketing and applying cellular products.

A consequence of this restrictive philosophy, even not consumer friendly policy, in certain countries is that it favours the growing international medical tourism and the loss of new applied medical PoC know-how in over-regulated countries, while patients wonder each time more why they cannot have the same treatment in their home country.

\section{Disclaimer}

Although we have cited various regulations in this overview, it does not mean that any regulatory agency mentioned is sharing the opinion expressed in this summary.

\section{References}

1. Alexey Bersenev (2016) What does the Cures Act mean for regulation of cell therapy in US.

2. Mark Berman, Elliot Lander (2017) A Prospective Safety Study of Autologous Adipose-Derived Stromal Vascular Fraction Using a Specialized Surgical Processing System.

3. Bhansali A, Upreti V, Walia R, Gupta V (2014) Efficacy and safety of autologous bone marrow derived hematopoietic stem cell transplantation in patients with type 2 DM: A 15 month's follow-up study. Indian J Endocrinol Metab 18(6):838-845.

4. Michalek J, Moster R, Lukac L, Proefrock K, Petrasovic M, et al. (2015) Autologous adipose tissue-derived stromal vascular fraction cells application in patients with osteoarthritis. Cell transplant.

5. Alan Trounson, Rahul G Thakar, Geoff Lomax, Don Gibbons (2011) Clinical trials for stem cell therapies. BMC Medicine.

6. Christopher J Centeno, Hasan Al Sayegh, Michael D Freeman (2016) A multi-center analysis of adverse events among two thousand, three hundred and seventy two adult patients undergoing adult autologous stem cell therapy for orthopaedic conditions. International Orthopaedics 40(8): 1755-1765.

7. Stem cells had shown safe, beneficial for chronic stroke patients (2016).

8. Xupin Jiang, Hengshu Zhang, Miao Teng (2016) Effectiveness of Autologous Stem Cell Therapy for the Treatment of Lower Extremity Ulcers. Medicine 95(11): e2716. 


\section{Anatomy Physiology \& biochemistry international journal}

9. Julien Freitag Dan Bates, Richard Boyd, Kiran Shah, Adele Barnard (2016) Mesenchymal stem cell therapy in the treatment of osteoarthritis: reparative pathways, safety and efficacy - a review. BMC Musculoskeletal Disorders 17: 230.
10. Sophie Vériter, Wivine André, Najima Aouassar, Hélène Antoine Poirel Aurore Lafosse (2015) Human Adipose-Derived Mesenchymal Stem Cells in Cell Therapy: Safety and Feasibility in Different "Hospital Exemption" Clinical Applications.

Your next submission with Juniper Publishers will reach you the below assets

- Quality Editorial service

- Swift Peer Review

- Reprints availability

- E-prints Service

- Manuscript Podcast for convenient understanding

- Global attainment for your research

- Manuscript accessibility in different formats

( Pdf, E-pub, Full Text, Audio)

- Unceasing customer service

Track the below URL for one-step submission https://juniperpublishers.com/online-submission.php 